\title{
GmRAR1 and GmSGT1 Are Required for Basal, $R$ Gene-Mediated and Systemic Acquired Resistance in Soybean
}

\author{
Da-Qi Fu, Said Ghabrial, and Aardra Kachroo \\ Department of Plant Pathology, University of Kentucky, Lexington 40546, U.S.A. \\ Submitted 15 July 2008. Accepted 1 September 2008.
}

\begin{abstract}
RAR1, SGT1, and HSP90 are important components of effector-triggered immunity (ETI) in diverse plants, where RAR1 and SGT1 are thought to serve as HSP90 co-chaperones. We show that ETI in soybean requires RAR1 and SGT1 but not HSP90. Rsv1-mediated extreme resistance to Soybean mosaic virus (SMV) and Rpg-1b-mediated resistance to Pseudomonas syringae were compromised in plants silenced for $G m R A R 1$ and $G m S G T 1-2$ but not GmHSP90. This suggests that RAR1- or SGT1-dependant signaling is not always associated with a dependence on HSP90. Unlike in Arabidopsis, SGT1 in soybean also mediates ETI against the bacterial pathogen $P$. syringae. Similar to Arabidopsis, soybean RAR1 and SGT1 proteins interact with each other and two related HSP90 proteins. Plants silenced for $G m H S P 90$ genes or GmRARI exhibited altered morphology, suggesting that these proteins also contribute to developmental processes. Silencing GmRARI and GmSGT1-2 impaired resistance to virulent bacteria and systemic acquired resistance (SAR) in soybean as well. Because the Arabidopsis rarl mutant also showed a defect in SAR, we conclude that RAR1 and SGT1 serve as a point of convergence for basal resistance, ETI, and SAR. We demonstrate that, although soybean defense signaling pathways recruit structurally conserved components, they have distinct requirements for specific proteins.
\end{abstract}

Additional keywords: Rpg1-b.

Plants defend themselves by inducing specific responses to diverse microbial pathogens, including basal defense against virulent pathogens, resistance $(\mathrm{R})$ protein-mediated immunity against avirulent pathogens, and systemic acquired resistance (SAR) against secondary pathogens. The type of resistance induced is determined by the mode of pathogen perception, which relies upon the recognition of pathogen-derived molecules by plant proteins. Basal or pathogen-associated molecular pattern (PAMP)-triggered immunity (PTI) is induced when pattern recognition receptors in the plant recognize conserved

Corresponding author: A. Kachroo; Telephone: +1.859.257.7445; Fax: +1.859.323.1961; E-mail: apkach2@uky.edu

Nucleotide sequence data are available in the NCBI database under the following accession numbers: GmRAR1 (FJ222386), GmSGT1-1 (FJ222387), GmSGT1-2 (FJ222388), GmHSP90-2 (FJ222389), GmHSP90-1 (FJ222390).

* The $\boldsymbol{e}$-Xtra logo stands for "electronic extra" and indicates that three supplemental figures are published online and that Figures 1 and 2 appear in color online. microbial factors, termed PAMPs (Ausubel 2005). Speciesspecific or effector-triggered immunity (ETI) is induced when a strain-specific avirulent (AVR) protein from the pathogen associates directly or indirectly with a cognate plant $\mathrm{R}$ protein (Chisholm et al. 2006; Dangl and Jones 2001). This AVR-R association not only induces defense in the infected tissues but also can initiate SAR to immunize systemic tissues against secondary infections by related or unrelated pathogens (Durrant and Dong 2004). Downstream signaling initiated by these events eventually restricts spread of the respective pathogen.

Several downstream components that mediate ETI have been identified (Austin et al. 2002; Azevedo et al. 2002; Century et al. 1995; Parker et al. 1996; Shirasu and Schulze-Lefert 2003). Of these, the RAR1 (required for Mla12-mediated resistance), SGT1 (suppressor of the G2 allele of $s k p 1$ ), and HSP90 (heat shock protein 90) proteins are recruited by structurally diverse $\mathrm{R}$ proteins and mediate resistance against a variety of pathogens, including viruses, bacteria, oomycetes, and fungi (Schulze-Lefert 2004). These proteins physically interact with each other and are thought to function in maintaining $\mathrm{R}$ protein stability under various conditions (Azevedo et al. 2002; Bieri et al. 2004; Hubert et al. 2003; Takahashi et al. 2003; Tornero et al. 2002).

RAR1 was first identified as a protein required for $R$ genemediated resistance to powdery mildew in barley (Torp and Jørgensen 1986). RAR1 proteins are characterized by the presence of two similar but distinct cysteine- and histidine-rich, zinc-binding domains (CHORD I and II) (Shirasu et al. 1999). In addition to the CHORD domains, plant RAR1 proteins contain a third cysteine- and histidine-rich zinc-binding domain designated the $\mathrm{CCCH}$ motif (Heise et al. 2007; Shirasu et al. 1999).

SGT1, identified as an RAR1-interacting protein, also regulates R protein-mediated defense signaling (Austin et al. 2002; Azevedo et al. 2002; Gray et al. 2003; Tör et al. 2002). Recent evidence has shown that SGT1 positively regulates the steadystate accumulation of the potato Rx protein in transgenic Nicotiana benthamiana plants (Azevedo et al. 2006). SGT1 has also been shown to negatively regulate the preinfection levels of $\mathrm{R}$ proteins in Arabidopsis (Holt et al. 2005). A characteristic feature of the SGT1 protein is the presence of three conserved domains: a tetratricopeptide (TPR) domain, a CS (CHORD SGT1) motif, and an SGT1-specific sequence (SGS). TPR motifs consist of 34 amino acid (aa) degenerate repeats found in proteins involved in cell cycle control, RNA biogenesis, and heat shock response (Goebl and Yanagida 1991; Lamb et al. 1995). The CS and SGS domains mediate binding to the CHORD II domain of RAR1 and the leucine-rich repeat domain of R proteins (Bieri et al. 2004), respectively. In addition 
to ETI, RAR1 and SGT1 also participate in other modes of immunity; RAR1 is involved in PTI to virulent pathogens (Holt et al. 2005; Shang et al. 2006; Wang et al. 2008) while SGT1 is known to mediate SAR in Arabidopsis (Truman et al. 2007).

In animals, TPR and CS motifs are also found in co-chaperone proteins that associate with HSP90, suggesting a similar function for SGT1 (Muskett and Parker 2003). Indeed, both RAR1 and SGT1 interact with the evolutionarily conserved HSP90 chaperone involved in protein folding, assembly, and transport (Csermely et al. 1998). Plants encode multiple isoforms of HSP90 and, of these, the most abundant cytosolic isoforms have been implicated in $\mathrm{R}$ protein functionality (Bhattarai et al. 2007; Hubert et al. 2003; Kanzaki et al. 2003; Liu et al. 2004; Lu et al. 2003; Takahashi et al. 2003). Loss of cytosolic HSP90 function leads to the rapid degradation of many R proteins, resulting in susceptibility (Holt et al. 2005; Hubert et al. 2003; Lu et al. 2003; Takahashi et al. 2003). HSP90 proteins also participate in plant responses to abiotic stresses, including heat, drought, and salt tolerance (Liu et al. 2006; Sangster et al. 2007; Yamada et al. 2007).

Here, we identified the soybean (Glycine max) orthologs of RARl, SGT1, and HSP9O and analyzed their defense-related functions using virus-induced gene silencing (VIGS). We have previously shown that a VIGS vector based on the Bean pod mottle comovirus (BPMV) can effectively silence endogenous soybean genes (Kachroo et al. 2008; Zhang and Ghabrial 2006). Using this BPMV-based vector to silence the GmRARl, GmSGT1, and GmHSP90 genes, we demonstrate a previously undefined role for GmRAR1 and GmSGT1-2 in mediating three different modes of immunity, including PTI, ETI, and SAR in soybean. We further show that the Rsvl-mediated extreme resistance (ER) to Soybean mosaic virus (SMV) differs significantly in its requirement for RAR1, SGT1, and HSP90 chaperones compared with $R x$-mediated ER to Potato virus $X$ (PVX). We demonstrate that GmRAR1 and GmSGT1-2 are also required for $R p g-1 b$-mediated resistance to Pseudomonas syringae as well as SAR in soybean. This is the first report establishing a role for RAR1 in SAR and SGT1 for resistance to $P$. syringae in plants. We conclude that, in spite of recruiting conserved components, soybean defense signaling pathways deviate significantly from those in other plant species.

\section{RESULTS}

Identifying the soybean orthologs of RARI and SGT1.

To identify the soybean orthologs of $R A R 1$, we screened the G. max expressed sequence tags (EST) database for sequences that shared similarities with Arabidopsis RARl. In all, 17 different EST that showed 56 to $93 \%$ identity to Arabidopsis RAR1 were obtained. Assembly of these 17 EST identified a 1,250-bp sequence containing a single open reading frame (ORF) of 675 bp. Analysis of the predicted 224-aa-long protein (GmRAR1) detected two 64-aa-long CHORD domains, one from V6 through T70 and the other from P155 through N219 (Supplemental Fig. 1; marked by asterisks). Multiple sequence alignments and phylogenetic analysis with other plant RAR1 proteins showed 65 to $68 \%$ identity to RAR1 from Arabidopsis (At), tobacco (Nt), and barley (Hv) (Fig. 1A and data not shown). GmRAR1 also contained the plant-specific $\mathrm{CCCH}$ motif (Shirasu et al. 1999). The GmRAR1 CCCH motif is 22 aa long rather than the usual length of 20 aa. Our analysis indicates that the soybean genome encodes at least one RAR1 protein.

Sequence analysis also identified over 80 EST encoding putative candidates with significant similarities to Arabidopsis $S G T 1 b$. These were assembled into two sequences, designated GmSGT1-1 (1,370 bp) and GmSGT1-2 (1,293 bp). Each contained a single ORF, 1,086 bp (GmSGT1-1) and 1,080 bp
(GmSGT1-2) encoding proteins with approximately $66 \%$ identity to each other (Supplemental Fig. 2). Similar to SGT1 proteins from other systems, both GmSGT1-1 and GmSGT1-2 contained the conserved TPR, CS, and SGS domains (Azevedo et al. 2002) that shared 73,71 , and $85 \%$ sequence identities, respectively. Multiple sequence alignments and phylogenetic analysis showed that GmSGT1-1 is 60 to $65 \%$ identical to SGT1 from Arabidopsis (AtSGT-1a and 1b), tobacco (NbSGT), and barley (HvSGT). On the other hand, GmSGT12 is more closely related to HvSGT and NbSGT (>70\% identity) than to AtSGT1a or AtSGT1b (65\% identity) (data not shown). This analysis identified two genes encoding SGT1like proteins in soybean.

\section{GmRAR1 and GmSGT1 proteins interact \\ in yeast two-hybrid assays.}

Because RAR1 and SGT1 are known to interact with each other (Azevedo et al. 2002), we first tested the interaction between the putative GmRAR1 and GmSGT1 proteins using the yeast two-hybrid assay. GmRAR1 was expressed as a fusion with the GAL4-binding domain (R-BD) and GmSGT1-1 or

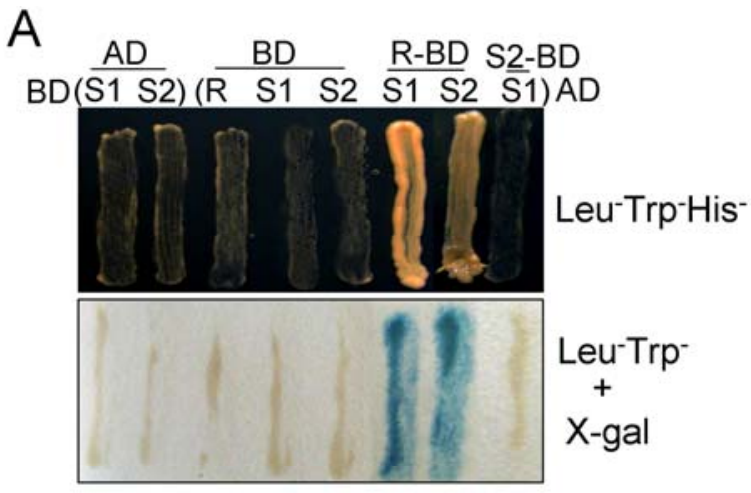

B
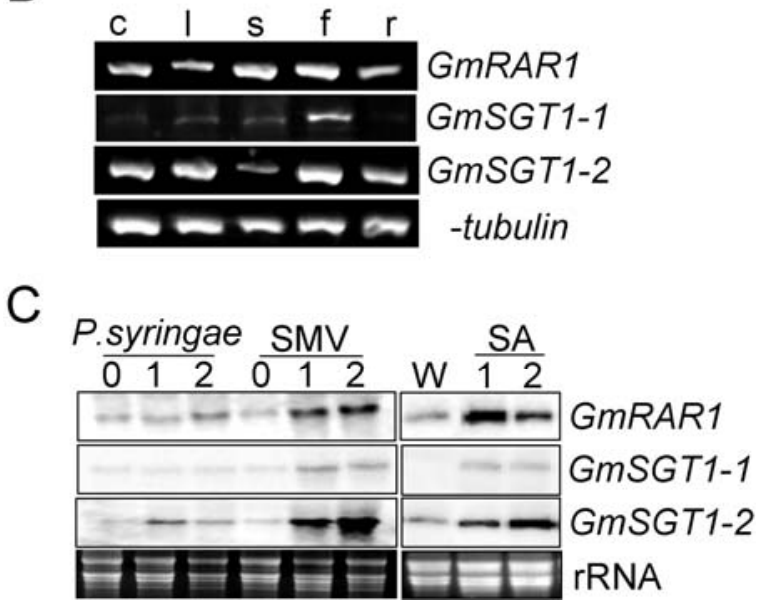

Fig. 1. Analysis of GmRAR1, GmSGT1-1, and GmSGT1-2. A, Protein-protein interactions between GmRAR1 and GmSGT1-1 and GmSGT1-2 and between GmSGT1-1 and GmSGT1-2 using yeast two-hybrid analysis. Abbreviations used for transformed yeast strains are S1/S2-AD (GAL4-ADGmSGT1-1/ 2), R/S2-BD (GAL4-BD-GmRAR1 or GAL4-BD-GmSGT12), BD (GAL4-BD vector with no fused protein), and AD (GAL4-AD vector with no fused protein). B, Gene expression as detected by reverse-transcription polymerase chain reaction analysis in flowers (f), leaves (l), stems (s), cotyledons (c), and roots (r) of healthy soybean plants (cv. Essex), and C, Northern blot analysis of RNA from plants inoculated with Pseudomonas syringae (cv. Harosoy) or Soybean mosaic virus (SMV)-G2 (1 or 2 days postinoculation) or treated with water (W) or salicylic acid (SA) (cv. Essex). Ethidium bromide staining of rRNA was used as a loading control. 
GmSGT1-2 were expressed as fusions with the GAL4-activating domain (S1/S2-AD) or the GAL4-binding domain (S1/S2$\mathrm{BD})$. As expected, yeast carrying R-AD plus BD vector or S1/S2-BD plus AD vector did not grow on media lacking leucine, tryptophane, and histidine (Leu ${ }^{-} \operatorname{Trp}^{-} \mathrm{His}^{-}$), where histidine is one of the selectable markers for interaction. In contrast, R$\mathrm{BD}$ and $\mathrm{S} 1-\mathrm{AD}$ or R-BD and S2-AD containing cells grew on the $\mathrm{Leu}^{-} \mathrm{Trp}^{-} \mathrm{His}^{-}$medium, suggesting that GmRAR1 interacts with GmSGT1-1 and GmSGT1-2 (Fig. 1A, upper panel). A positive interaction was further confirmed by 5-bromo-4chloro-3-indolyl- $\beta$-D-galactose (X-gal) staining of cells grown on $\mathrm{Leu}^{-} \mathrm{Trp}^{-}$media, where only the cells carrying R-BD and S1/S2-AD turned blue (Fig. 1A, lower panel). Yeast twohybrid analysis did not detect any interaction between GmSGT1-1 and GmSGT1-2 (Fig. 1A, S2-BD + S1-AD).

\section{GmRARI and GmSGT1 are inducible}

by pathogen infection and salicylic acid application.

To characterize the defense-related roles of GmRARl, GmSGT1-1, and GmSGT1-2, we first examined their expression in various tissues of soybean plants and in response to
A

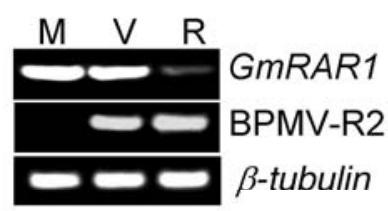

B

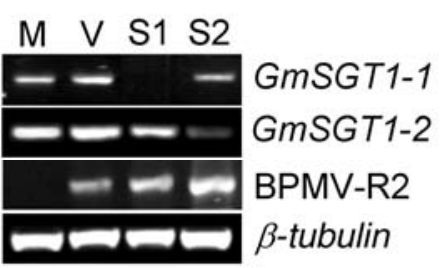

E

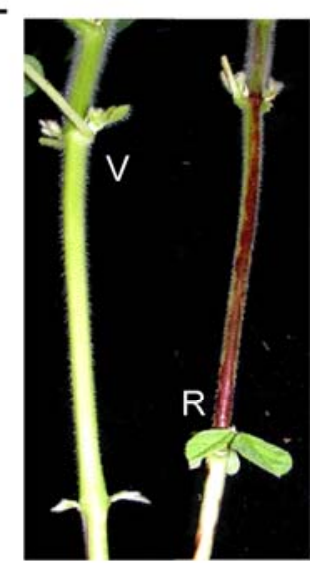

C

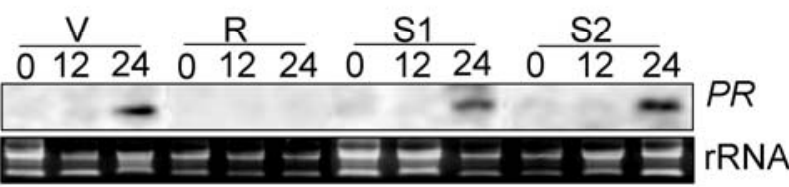

D

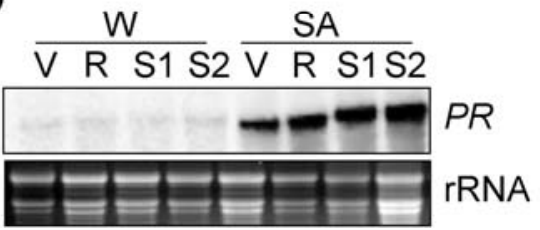

Fig. 2. Analysis of soybean plants silenced for GmRAR1 (R), GmSGT1-1 (S1), or GmSGT1-2 (S2). Soybean plants (cv. Essex) were inoculated with empty vector (V) or recombinant vectors carrying fragments from GmRAR1 (R), GmSGT1-1 (S1), or GmSGT1-2 (S2). Mock-inoculated plants (M) were included as control. A, GmRARl expression in M, V, or R plants. B, GmSGT1-1 and GmSGT1-2 expression in $\mathrm{M}, \mathrm{V}, \mathrm{S} 1$, and $\mathrm{S} 2$ plants. Reverse-transcription polymerase chain reaction analysis was carried out on cDNA prepared from total RNA from leaves. Bean pod mottle comovirus (BPMV)-RNA2 was amplified by using RNA2-specific primers (BPMV-R2) and $\beta$-tubulin levels were used as internal control for cDNA amounts. C, Northern blot analysis of pathogenesis-related $(P R)$ gene expression in $\mathrm{V}, \mathrm{R}, \mathrm{S} 1$, and $\mathrm{S} 2$ plants before (0) or 12 and $24 \mathrm{~h}$ postinoculation with Pseudomonas syringae (cv. Harosoy) and D, in response to exogenous water (W) or salicylic acid (SA) application (cv. Essex). Ethidium bromide staining of rRNA was used as a loading control. E, Morphological phenotypes of stem from $\mathrm{V}$ and $\mathrm{R}$ plants. Stems from $\mathrm{R}$ plants show colored streaks. pathogen infection. Reverse-transcription polymerase chain reaction (RT-PCR) analysis detected higher levels of GmRARl transcript in flowers and stems compared with those in leaves, cotyledons, or roots (Fig. 1B). Northern blot analysis showed that $G m R A R 1$ expression was induced very slightly 2 days postinoculation with $P$. syringae. In contrast, SMV infection as well as exogenous salicylic acid (SA) application induced much higher expression of GmRARl (Fig. 1C).

GmSGT1-1 was expressed at low levels in flowers, even lower levels in leaves and stems, and barely detectable levels in cotyledons or roots. In contrast, GmSGT1-2 was expressed at high levels in cotyledons, leaves, and flowers; low levels in roots; and even lower levels in stems (Fig. 1B). GmSGT1-1 was not induced by $P$. syringae infection but was slightly induced by SMV infection as well as exogenous SA. In contrast to GmSGT1-1, GmSGT1-2 was induced in response to infections by both $P$. syringae and SMV, although the $P$. syringaeinduced levels of GmSGT1-2 transcripts were much lower than those induced by SMV. Exogenous SA also induced the expression of GmSGT1-2 (Fig. 1C).

\section{Silencing the soybean $G m R A R 1$ and $G m S G T 1-2$ genes impairs $R s v 1$-mediated resistance to SMV.}

We next studied the effects of silencing GmRARl and GmSGT1 on defense gene expression and pathogen resistance in soybean. The BPMV vector $(\mathrm{V})$ and the recombinant vectors targeting GmRARl (R), GmSGT1-1 (S1), and GmSGT1-2 (S2) were inoculated onto soybean plants, and cDNA from leaves of the respective plants was analyzed for expression of BPMVRNA2, $\beta$-tubulin, and the target gene. High levels of viral transcripts were detected in leaf tissues from V, R, S1, and S2 plants. Both $\mathrm{V}$ and mock-inoculated (M) plants expressed similar levels of GmRAR1, GmSGT1-1, and GmSGT1-2 transcripts (Fig. 2A and B). The R, S1, and S2 plants showed no or greatly reduced levels of GmRAR1, GmSGT1-1, and GmSGT1-2 transcripts, respectively (Fig. 2A and B). Silencing was specific for the target gene, even in the case of the two GmSGT1 isoforms, such that GmSGT1-1 and GmSGT1-2 were specifically silenced in S1 or S2 plants, respectively (Fig. 2B).

Silencing of GmSGT1-1 or GmSGT1-2 did not alter plant morphology but plants silenced for GmRARl developed a dark-colored streak on their stems (Fig. 2E). The altered morphology of $\mathrm{R}$ stems did not affect plant reproductive health or seed set (data not shown).

The Arabidopsis rarl mutant is defective in its ability to induce pathogenesis-related $(P R)$ gene expression following pathogen infection (Muskett et al. 2002); therefore, we analyzed the defense-related $P R$ expression in $\mathrm{V}, \mathrm{R}, \mathrm{S} 1$, and $\mathrm{S} 2$ plants. As expected (Kachroo et al. 2008), inoculation of BPMV vector did not induce $P R$ expression (Fig. 2C and D). Silencing GmRARl but not GmSGT1-1/2 impaired the ability of soybean plants to induce $P R$ genes in response to infection by a virulent strain of $P$. syringae (Fig. 2C). Interestingly, the $\mathrm{R}, \mathrm{S} 1$, and $\mathrm{S} 2$ plants induced $P R$ expression in response to exogenous SA similarly to the V plants (Fig. 2D). Taken together, these results show that, similar to Arabidopsis, the pathogen-induced expression of $P R$ requires $G m R A R l$ in soybean.

$R s v 1$, a single dominant gene originally derived from soybean PI96983 (Chen et al. 1991) confers ER against SMV strains G1 through G6 and C14, but not against G7 or G7a (Buzell and Tu 1984). The Rsvl-mediated ER is not associated with visible hypersensitive response (HR), induction of $P R$ expression, or spread of the virus in noninoculated tissues (Buzell and Tu 1984; Lim 1985). To examine the role of GmRARl, GmSGT1-1, and GmSGT1-2 in Rsv1-mediated resistance to $\mathrm{SMV}$, we silenced these genes in plants carrying the Rsvl locus 
(Essex-Rsv1). Silencing of the respective genes in Essex-Rsv1 plants was confirmed by RT-PCR analysis (data not shown). Enzyme-linked immunosorbent assay (ELISA) detected similar levels of BPMV in vector-inoculated Essex $\left(r s v l_{\mathrm{V}}\right)$ and Essex-Rsvl $\left(R s v l_{\mathrm{V}}\right)$ plants as well as Essex-Rsvl plants silenced for GmRARl $\left(R s v 1_{\mathrm{R}}\right), G m S G T 1-1\left(R s v 1_{\mathrm{S} 1}\right)$, or GmSGT1-2 $\left(R s v l_{\mathrm{S} 2}\right)$ (data not shown). Inoculation with SMV-G2 induced systemic mosaic in the susceptible plants $(r s v l)$ but produced no symptoms on the resistant plants (Rsv1) (Fig. 3A and B). This was consistent with accumulation of SMV in the systemic tissues of $r s v l_{\mathrm{V}}$ but not $R s v l_{\mathrm{V}}$ plants (Fig. 3D). Interestingly, unlike $R s v l_{\mathrm{V}}$, the $R s v 1_{\mathrm{R}}$ and $R s v 1_{\mathrm{S} 2}$ plants developed necrotic lesions on both inoculated (Fig. 3A) and systemic leaves (Fig. 3B) as well as enhanced symptom severity (severe mottling, stunting, and deformation), which is reminiscent of the synergistic interaction between BPMV and SMV. Enhancement of BPMV titer in plants that are doubly infected with BPMV and SMV is a characteristic feature of the ensuing synergism between the two viruses (Anjos et al. 1992). Indeed, Northern analysis showed that $R s v l_{\mathrm{S} 2}$ plants contained higher levels of BPMV-RNA2 compared with $R s v 1_{\mathrm{V}}$ plants (Fig. 3C). The $R s v 1_{\mathrm{R}}$ and $R s v 1_{\mathrm{S} 2}$ plants also accumulated SMV in their systemic tissues (Fig. 3D). In contrast, $R s v 1_{\mathrm{S} 1}$ plants were resistant to SMV-G2 because they did not develop any enhancement of visual symptoms upon inoculation with SMV (data not shown) or accumulate SMV in their systemic tissues (Fig. 3D). Western analysis and quantitative ELISA further confirmed the accu- mulation of SMV in systemic tissues of $R s v l_{\mathrm{R}}$ and $R s v l_{\mathrm{S} 2}$ plants (Fig. 3E and F). Interestingly, and in contrast to the SMVinoculated $R s v l_{\mathrm{V}}$ or $R s v l_{\mathrm{S} 1}$ plants, $R s v 1_{\mathrm{R}}$ and $R s v l_{\mathrm{S} 2}$ plants also induced $P R$ expression (Fig. 3D). Taken together, these results suggest that loss of GmRARl or GmSGT1-2 compromises soybean defense and impairs $R s v 1$-mediated ER to SMV-G2.

\section{Role of GmRAR1 and GmSGT1}

in soybean defense against $P$. syringae.

We next silenced GmRARl and the two GmSGT1 genes in soybean plants carrying Rpgl-b (cv. Harosoy) to examine their roles in defense against $P$. syringae. Healthy and silenced plants (confirmed by RT-PCR analysis) were assessed for their response to virulent (vir) or avirulent $(a v r B)$ strains of bacteria. Both R and S2 plants supported sixfold more growth of $a v r B$ bacteria compared with $\mathrm{V}$ plants (Fig. 4A). The R and S2 plants also showed increased susceptibility to the vir strain, accumulating eight- and fivefold more bacteria, respectively (Fig. 4B). In contrast, S1 plants supported only slightly more growth of $a v r B$ or vir $P$. syringae than $\mathrm{V}$ plants. These results show that, similar to the Arabidopsis RAR1, GmRARl participates in both $R$-mediated and basal resistance to bacteria in soybean. Interestingly, GmSGT1-2 is also required for both $R$ mediated and basal resistance to bacteria. This is in contrast to Arabidopsis, where a role for SGT1 in defense against $P$. syringae has not been reported.

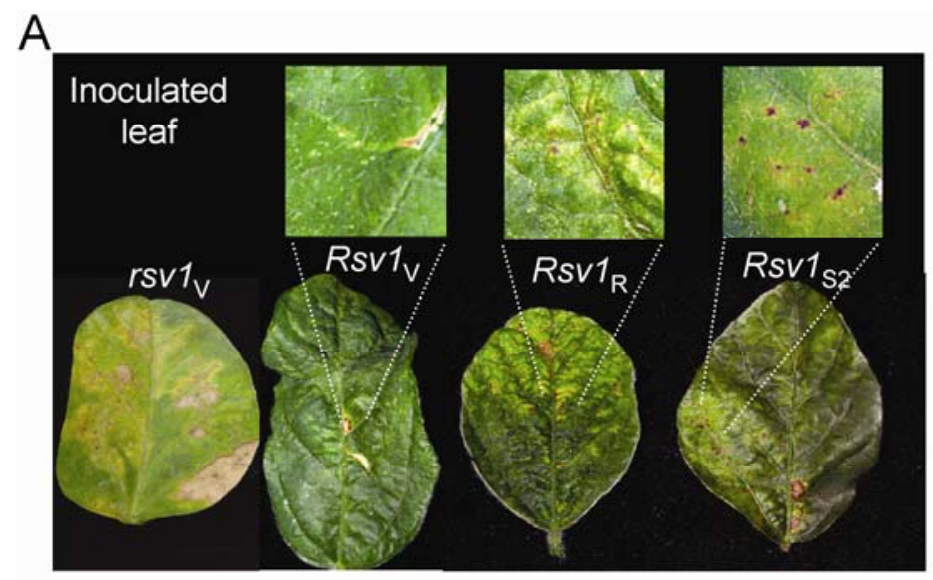

C

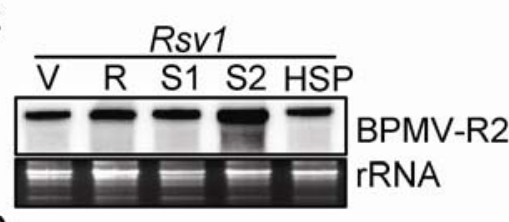

$\mathrm{D}$

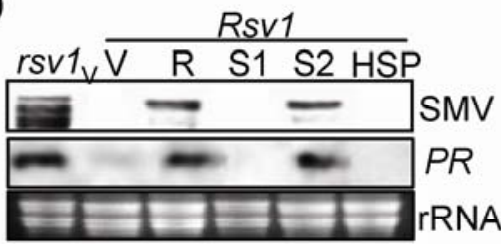

$\mathrm{E}$

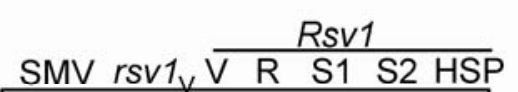

B
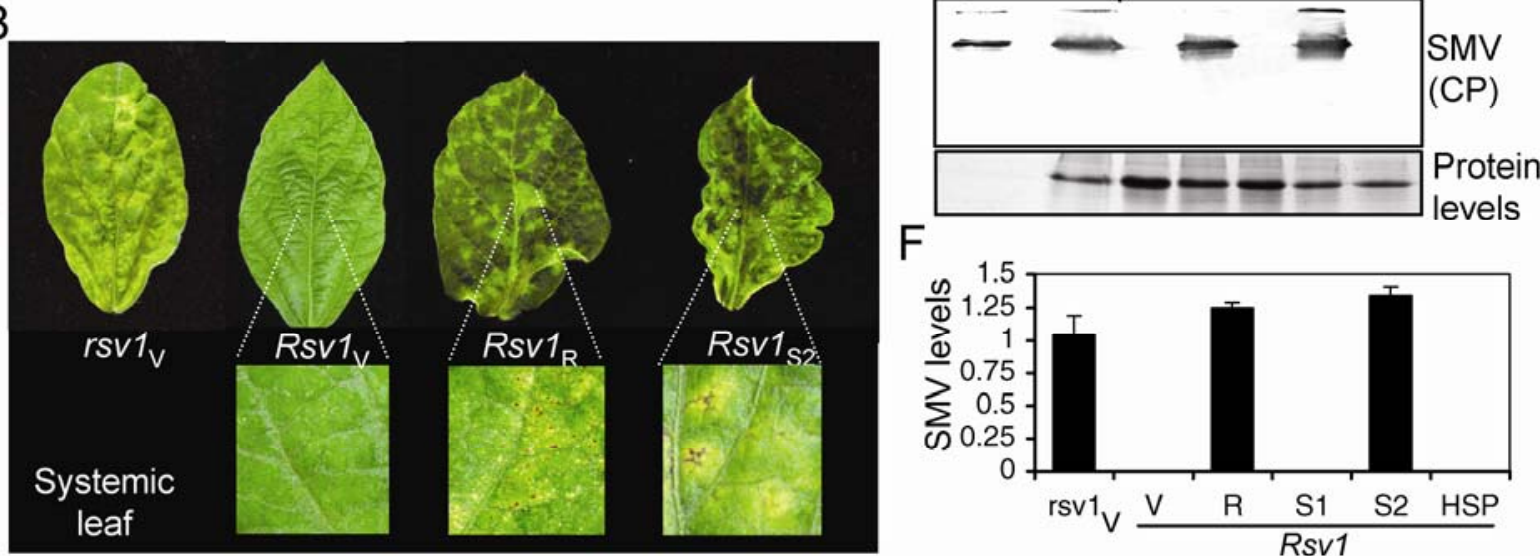

$\mathrm{F}$

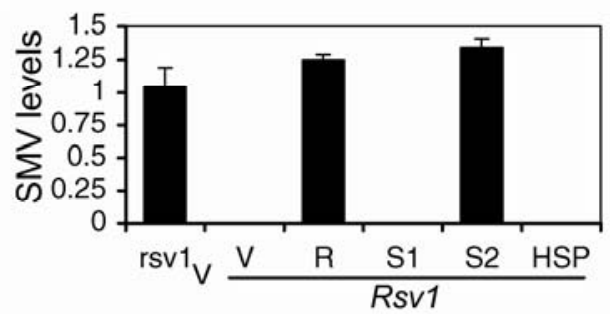

Fig. 3. Response to Soybean mosaic virus (SMV) infection in Rsv1 plants silenced for GmRAR1 (Rsv $\left.1_{\mathrm{R}}\right), G m S G T 1-1\left(R s v 1_{\mathrm{S} 1}\right), G m S G T 1-2\left(R s v 1_{\mathrm{S} 2}\right)$, or $G m H s p 90-1 / 2\left(R s v 1_{\mathrm{Hsp}}\right)$. Virus symptoms on $\mathbf{A}$, inoculated or $\mathbf{B}$, systemic leaves of vector-inoculated Essex $\left(r s v 1_{\mathrm{V}}\right)$ or Essex-Rsv1 $\left(R s v 1_{\mathrm{V}}\right), R s v 1_{\mathrm{R}}$, and $R s v 1_{\mathrm{S} 2}$ plants 14 days postinoculation with SMV-G2. C, Northern blot analysis of RNA from $r s v 1_{\mathrm{V}}, R s v 1_{\mathrm{V}}, R s v 1_{\mathrm{R}}, R s v 1_{\mathrm{S} 1}, R s v 1_{\mathrm{S} 2}$, and $R s v 1_{\mathrm{Hsp}}$ plants showing levels of Bean pod mottle comovirus or D, SMV and pathogenesis-related $(P R)$ gene, 14 days postinoculation with SMV-G2. Ethidium bromide staining of rRNA was used as a loading control. E, Western blot and $\mathbf{F}$, enzyme-linked immunosorbent assay (ELISA) analysis to detect SMV in systemic tissues of $r s v 1_{\mathrm{V}}, R s v 1_{\mathrm{V}}, R s v 1_{\mathrm{R}}, R s v 1_{\mathrm{S} 1}, R s v 1_{\mathrm{S} 2}$, and $R s v 1_{\mathrm{Hsp}}$ plants 14 days postinoculation with SMV-G2. Total protein $(10 \mu \mathrm{g})$ from leaves was used for Western analysis and leaf extracts at a dilution of 1:1000 (wt/vol) were used for ELISA with antibodies against SMV coat protein. SMV levels are presented as ELISA values (absorbance at $405 \mathrm{~nm}$ ) with error bars indicating standard deviation $(n=3)$. 


\section{Role of GmRAR1 and GmSGT1 in SAR.}

Because the Arabidopsis sgtlb mutant is defective in the onset of SAR (Truman et al. 2007), we compared SAR in V, R, and S2 plants. GmRAR1 and GmSGT1-2 were silenced in cv. Harosoy, and silencing of the respective gene was confirmed by RT-PCR analysis (data not shown). The V, R, and S2 plants were first inoculated with $P$. syringae $(a v r B)$ or infiltrated with buffer $\left(\mathrm{MgCl}_{2}\right)$ and, 2 days later, systemic leaves were inoculated with vir bacteria. Comparison of bacterial (vir) proliferation showed reduced growth in $a v r B$ - versus $\mathrm{MgCl}_{2}$-infiltrated $\mathrm{V}$ plants, indicating that BPMV infection did not alter the SAR response (Fig. 4C). However, analysis of the $\mathrm{R}$ and $\mathrm{S} 2$ plants showed similar growth of vir bacteria in $\mathrm{MgCl}_{2^{-}}$and avrBinfiltrated plants (Fig. 4C). Because the SAR-related role of Arabidopsis RAR1 is not known, we evaluated SAR in Arabidopsis rarl plants. Wild-type (RARl; ecotype-Landsberg) and rarl mutant plants were inoculated with an avirulent strain of P. syringae (DC3000-avrRpt2) or injected with buffer $\left(\mathrm{MgCl}_{2}\right)$ and, 2 days later, systemic leaves were inoculated with a virulent strain of $P$. syringae (DC3000). Compared with the $\mathrm{MgCl}_{2-}$ infiltrated plants $\left(R A R l-\mathrm{MgCl}_{2}\right), R A R 1$ plants infiltrated with avrRpt2 (RARl-avrRpt2) supported reduced growth of the virulent strain in their systemic leaves (Fig. 4D), suggesting the proper onset of SAR. In contrast, rarl plants previously infected with avrRpt 2 bacteria supported growth of virulent bacteria similar to the $\mathrm{MgCl}_{2}$-infiltrated plants (Fig. 4D). These results suggest that RAR1 and SGT1 are required for SAR in both soybean and Arabidopsis.

\section{GmHSP90 proteins interact} with GmRAR1, GmSGT1-1, and GmSGT1-2.

Both RAR1 and SGT1 are known to physically associate with, and likely serve as co-chaperones of HSP90 proteins (Schulze-Lefert 2004). To isolate the soybean orthologs of
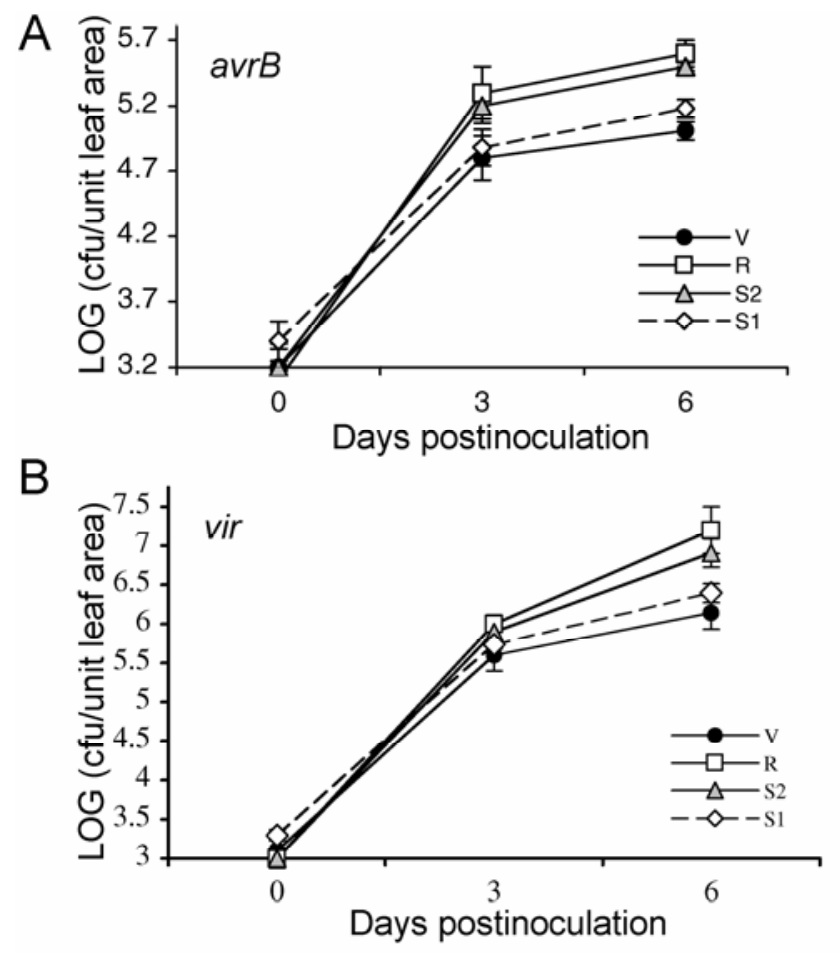

Fig. 4. Response to Pseudomonas syringae and systemic acquired resistance induction in soybean plants silenced for RARI or SGT1. A and B, Bacterial count in vector-inoculated (V) and GmRAR1 (R)-, GmSGT1-1 (S1)-, and GmSGT1-2 (S2)-silenced soybean plants. Plants were infiltrated with avirulent $(a v r B)$ or virulent (vir) strains of $P$. syringae pv. glycinea, respectively. C, Virulent bacterial counts in V, R, or S2 soybean plants that were previously infiltrated with $\mathrm{MgCl}_{2}$ or $a v r B$ bacteria. D, Virulent bacterial counts in wild-type $(R A R l)$ or mutant (rarl) Arabidopsis plants that were previously infiltrated with $\mathrm{MgCl}_{2}$ or an avirulent strain of $P$. syringae (avrRpt2). Bacterial numbers were determined by culturing extracts of four leaf discs from infected leaves at 0 or 3 days postinoculation as indicated, and are presented as a LOG value of CFU per unit leaf area. Error bars indicate standard deviation where $n=5$.

$H S P 90$, we screened the soybean sequence database and identified >100 EST that showed significant similarities to Arabidopsis HSP90. These EST were assembled to obtain several larger sequences, at least two of which are likely to encode full-length HSP90-like proteins. A 2,109-bp ORF in TC214290 (2,566 bp) was designated GmHSP90-1, and a 2,103-bp ORF in TC224706 (2,385 bp) was designated GmHSP90-2. The predicted proteins showed $94 \%$ identity to each other and up to $95 \%$ identity to other plant HSP90 proteins (Supplemental Fig. 3) (data not shown). Analysis for conserved domains detected the presence of a histidine kinase-like ATPase domain in the N-terminal portion (N14-D181 in GmHSP90-1 and N28-D182 in GmHSP90-2), and an HSP90 domain in the C-terminal portion (E184-I669 in GmHSP90-1 and E185-D700 in GmHSP90-2). TargetP analysis (Emanuelsson et al. 2000) of the N-terminal region did not detect any organellar targeting signal peptides, suggesting that both GmHSP90-1 and GmHSP90-2 are likely localized to the cytoplasm (data not shown).

Expression analysis of the two GmHSP9O genes using sequence-specific primers showed different expression patterns of the two isoforms in various soybean tissues. GmHSP90-1 but not GmHSP90-2 was expressed at high levels in leaves and cotyledons (Fig. 5A). In contrast, flowers showed high transcript levels of GmHSP90-2 but much reduced levels of GmHSP90-1. Similarly, GmHSP90-1 but not GmHSP90-2 was detected in cotyledons. Exogenous application of SA or inoculation with $P$. syringae or SMV did not alter the expression of GmHSP90 genes (Fig. 5A) (data not shown). However, both GmHSP90-1 and GmHSP90-2 were slightly induced by heat stress and repressed by cold stress. Drought stress did not alter the expression of either gene (Fig. 5A).

We used the yeast two-hybrid assay to test whether the two GmHSP90 proteins interact with GmRAR1, GmSGT1-1, or
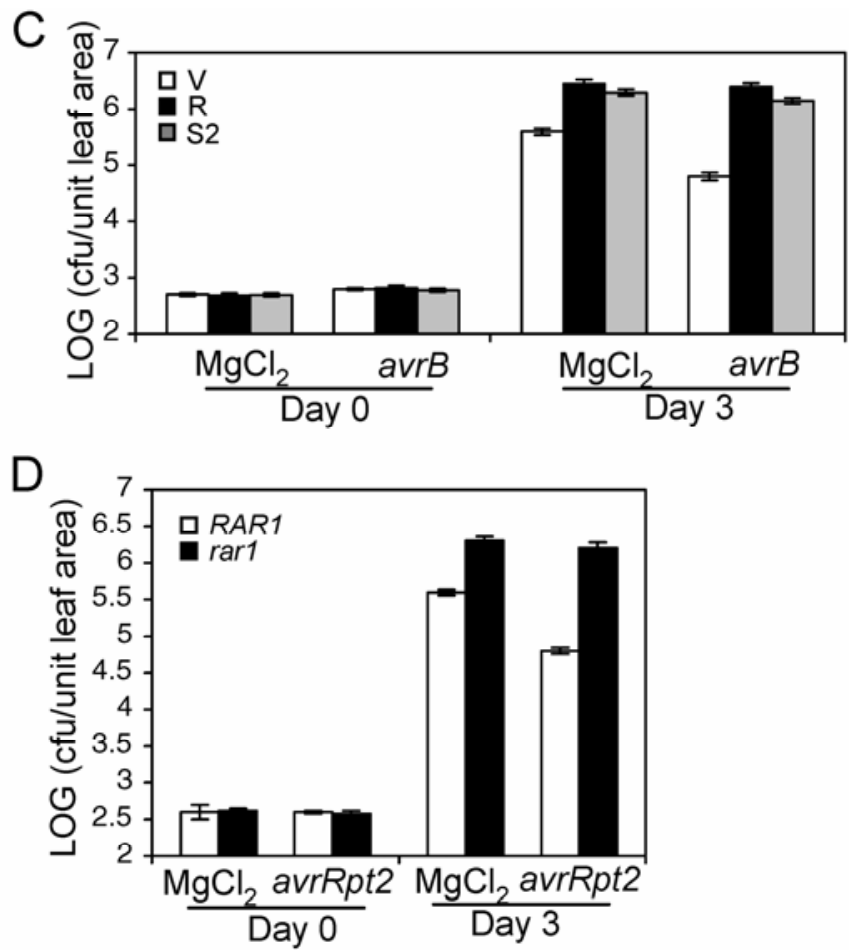
GmSGT1-2. HSP90 proteins from tobacco and Arabidopsis interact with the respective RAR1 and SGT1 proteins via their $\mathrm{N}$-terminal domains; therefore, we used polypeptide fragments containing the N-terminal halves of GmHSP90-1 and GmHSP90-2 (411 and 412 aa, respectively) for interaction studies. These $\mathrm{N}$-terminal fragments of the two proteins share 95\% identity and were expressed as GAL4 AD (H1/H2-AD) or $\mathrm{BD}(\mathrm{H} 1 / \mathrm{H} 2-\mathrm{BD})$ fusion proteins. Yeast transformed with H1/H2-AD plus S1-BD, S2-BD, or R-BD grew on Leu-Trp media (data not shown) and turned blue in the presence of $\mathrm{X}$ gal (Fig. 5B, lower panel). These cells also grew on Leu-Trp His $^{-}$media (Fig. 5B, upper panel). In contrast, yeast carrying H1-AD plus H2-BD grew only on $\mathrm{Leu}^{-} \mathrm{Trp}^{-}$media and did not turn blue in the presence of X-gal (data not shown), similar to control cells carrying $\mathrm{H} 1-\mathrm{BD} / \mathrm{H} 2-\mathrm{BD}$ plus $\mathrm{AD}$ vector. These results show that both GmHSP90-1 and GmHSP90-2 are capable of interacting with GmRAR1, GmSGT1-1, and GmSGT12 but not with each other.

\section{Silencing GmHsp90 alters \\ morphological but not defense phenotypes in soybean.}

The effect of silencing the GmHSP90 genes was tested to study the functionalities of the two GmHSP90 proteins. A 105bp fragment encoding the region between M1-L35 of GmHSP90-1 was cloned into pGG7R2V to generate a recombinant VIGS vector. Because this fragment is $85 \%$ identical to the sequence encoding M1-E35 of GmHSP90-2, we expected that the same VIGS vector would enable the simultaneous silencing of both GmHSP90-1 and GmHSP90-2. As predicted, RT-PCR analysis detected BPMV transcript in leaf tissues from V and GmHSP90-1- and GmHSP90-2-silenced (Hsp) plants, but not in $\mathrm{M}$ plants. The $\mathrm{V}$ and $\mathrm{M}$ plants expressed similar levels of GmHSP90-1 and GmHSP90-2. In contrast, no transcripts for GmHSP90-1 or GmHSP90-2 were detected in the leaves of Hsp plants (Fig. 5C). These data confirmed the silencing of GmHSP90-1 and GmHSP90-2 genes in soybean. Notably, the Hsp plants were severely stunted compared with $\mathrm{V}$ plants (Fig. 5D, panels i and ii) and showed profuse axillary growth (Fig. 5D, panel iii). Interestingly, these altered morphologies did not affect flower and seed development of the GmHSP90-silenced plants (data not shown).

The defense-related roles of GmHSP90-1 and GmHSP90-2 genes were analyzed by challenging GmHSP90-1- and GmHSP90-2-silenced Essex-Rsv1 (Rsv1 $1_{\mathrm{HSP}}$ ) plants with SMV. Silencing of GmHSP90-1 and GmHSP90-2 in Essex-Rsv1 plants was confirmed by RT-PCR analysis (data not shown). Analysis of BPMV levels detected similar levels in vectorinoculated Essex $\left(r s v 1_{\mathrm{V}}\right)$ or Essex-Rsvl $\left(R s v 1_{\mathrm{V}}\right)$ plants as well as the $R s v 1_{\text {HSP }}$ plants (data not shown). As expected, susceptible plants ( $r s v 1)$ but not resistant plants $(R s v l)$ developed systemic mosaic (data not shown) and accumulated SMV after inoculation with SMV-G2. Surprisingly, $R s v 1_{\mathrm{HSP}}$ plants did not develop any visual symptoms upon inoculation with SMV-G2 or accumulate SMV in their systemic tissues (Fig. 3D). This was further confirmed by Western analysis and ELISA of protein extracts from systemic tissues of the SMV-G2-inoculated $R s v l_{\mathrm{HSP}}$ plants (Fig. 3E and F). These data suggest that Rsv1mediated resistance to SMV does not require GmHSP90-1 or GmHSP90-2.

To examine the role of GmHSP90 proteins in basal and $R$ gene-mediated resistance to the bacterial pathogen $P$. syringae, we silenced GmHSP90-1 and GmHSP90-2 genes in plants carrying the Rpgl-b gene. Silencing of GmHSP90-1 and GmHSP90-2 in cv. Harosoy was confirmed by RT-PCR analysis (data not shown). Pathogen inoculations showed that Hsp plants supported growth of $a v r B$ or vir P. syringae similarly to the $\mathrm{V}$ plants (Fig. 5E). These results suggest that, in contrast to
GmRARI and GmSGT1-2, silencing GmHSP90-1 or GmHSP902 genes does not affect basal or $R$-mediated resistance to $P$. syringae.

\section{DISCUSSION}

In this study, we identified the soybean orthologs of $R A R l$, $S G T 1$, and HSP90 and showed that the RAR1 and SGT1 play central roles in PAMP-triggered, effector-triggered, and systemic immunity. We present evidence that both proteins are required for $R s v 1$-conferred ER to SMV and $R p g$ - $1 b$-mediated resistance to $P$. syringae. Rsvl-mediated resistance restricts SMV to the initially infected cells and, as a result, the host neither develops visible HR, a characteristic feature of induced $R$ mediated defenses, nor induces $P R$ gene expression (Buzzell and Tu 1984; Lim 1985; Nimchuk et al. 2003). Rsv1 plants silenced for GmRARl or GmSGT1-2 not only developed HRlike lesions on the inoculated and systemic leaves but also accumulated levels of SMV in their systemic tissues similar to those of susceptible plants lacking the Rsvl locus. Furthermore, these plants exhibited severe mottling, stunting, and leaf deformation symptoms characteristic of synergistic interaction between SMV and BPMV (Anjos et al. 1992). The predicted enhancement in accumulation of BPMV in the doubly infected plants was evident in the GmSGT1-2-silenced plants (Fig. 3C) but not in the $G m R A R l$-silenced plants. Elucidation of aspects of BPMV accumulation in the GmRAR1- and GmSGT1-2silenced plant would require systematic monitoring at various times following SMV infection.

The requirement for SGT1 in Rsv1-mediated ER is similar to that of the potato Rx protein, which also depends upon SGT1 to bestow ER against PVX (Botër et al. 2007; Peart et al. 2002). However, unlike Rsv1, Rx does not require the RAR1 protein for resistance signaling, although the stability of the Rx protein is reduced in the absence of RAR1 (Bieri et al. 2004).

Silencing GmRARl and GmSGT1-2 in plants containing $R p g-1 b$ also compromised resistance to $a v r B$-expressing $P$. syringae. The requirement for RAR1 by Rpg-1B resembles that of RPM1, which confers resistance to $P$. syringae expressing avrB or avrRpml in Arabidopsis (Bisgrove et al. 1994; Grant et al. 1995). However, RPM1 function does not require SGT1 in Arabidopsis (Austin et al. 2002). In fact, mutations in neither of the two Arabidopsis SGT1 isoforms impair ETI against any avirulent strain of $P$. syringae tested so far (Austin et al. 2002; Azevedo et al. 2006; Muskett and Parker 2003; Muskett et al. 2002; Tör et al. 2002). This suggests that the two isoforms either fulfill redundant functions or are not required for resistance to $P$. syringae in Arabidopsis. However, this does not seem to be the case in soybean, because silencing GmSGT1-2 alone impaired resistance to $P$. syringae in soybean.

Both Arabidopsis and soybean contain two SGT1 isoforms, which are 76 and $66 \%$ identical, respectively. Interestingly, only the GmSGT1-2 isoform participates in soybean $R$-mediated resistance. Silencing GmSGT1-1 did not alter soybean responses to avirulent SMV or $P$. syringae. This is similar to Arabidopsis, which appears to favorably employ only one isoform, AtSGT1b, for defense mediation (Austin et al. 2002; Tör et al. 2002). Interestingly, overexpression of AtSGTla can compensate for the loss of AtSGT1b, suggesting that basal levels of AtSGT1a are inadequate for mediating defense. Indeed, basal levels of the AtSGT1b protein are higher than those of AtSGT1a, and AtSGT1a can function in resistance signaling once it accumulates to a certain threshold level (Azevedo et al. 2006). This could also be the case in soybean, where basal levels of GmSGT1-1 transcript are much lower than those of GmSGT1-2. Similar to AtSGT1a, GmSGT1-1 is pathogen-inducible (Azevedo et al. 2006 and this work). GmSGT1-1 tran- 

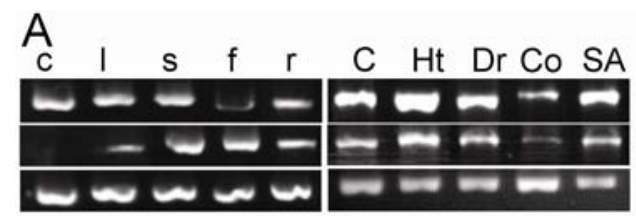

GmHsp90-1

GmHsp90-2

$\beta$-tubulin
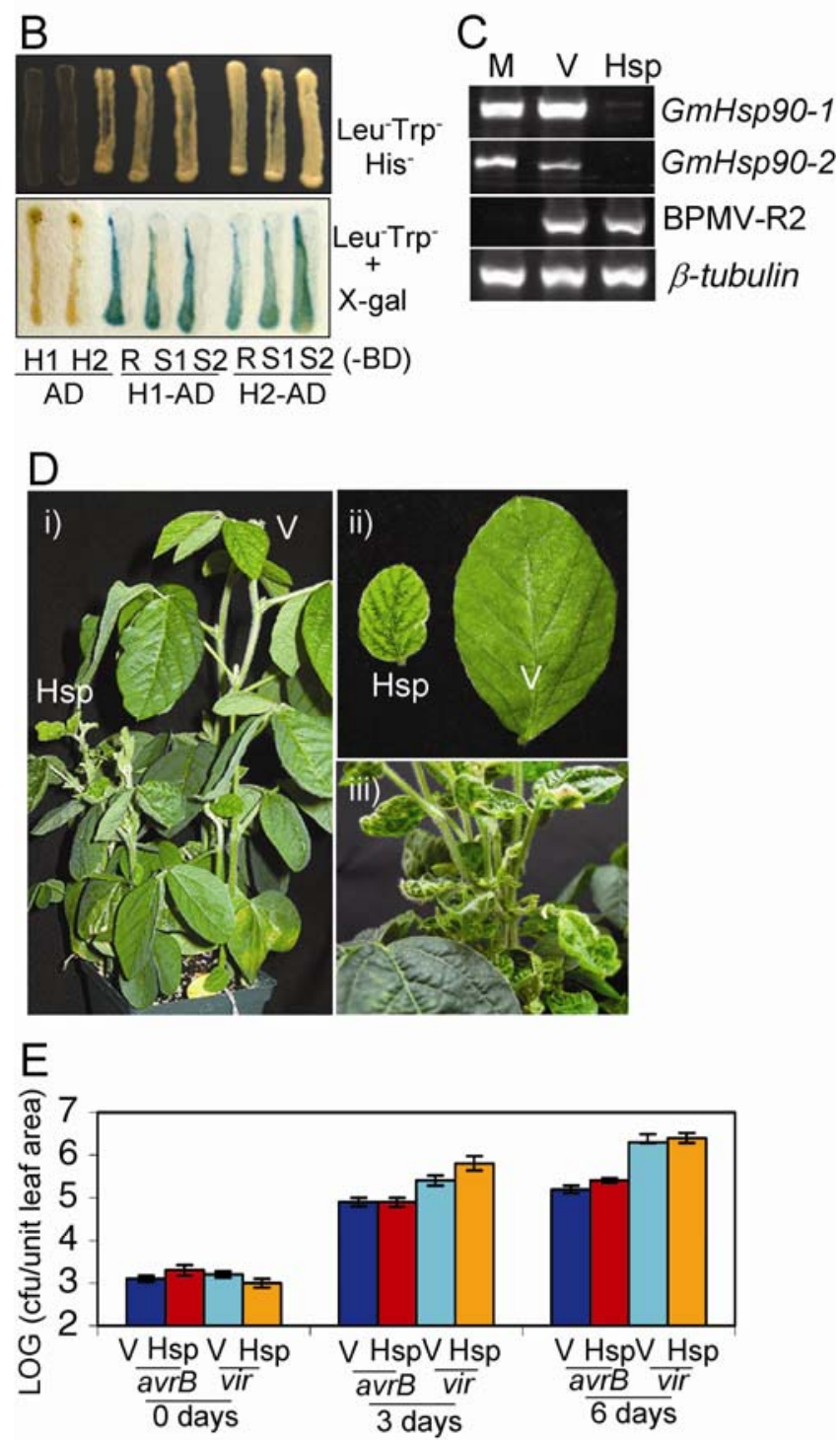

Fig. 5. Characterization of GmHsp90-1 and GmHsp90-2. A, GmHsp90-1 and $\mathrm{GmHsp90-2}$ expression in cotelydons (c), leaves (1), stems (s), flowers (f), and roots (r) of healthy soybean plants (cv. Essex) or in leaves of healthy plants (cv. Essex) (C) or those exposed to heat (Ht), drought (Dr), or cold (Co) stress, or treated with salicylic acid (SA). Total RNA (4 $\mu \mathrm{g}$ ) was used for reverse-transcription polymerase chain reaction (RT-PCR) analysis with gene-specific primers. Levels of $\beta$-tubulin were used as internal control to normalize the amount of cDNA in each reaction. $\mathbf{B}$, Interaction between GmRAR1, GmSGT1, and GmHsp90 proteins as detected by yeast two-hybrid analysis. Abbreviations used for transformed yeast strains are H1/H2-AD (GAL4-AD-GmHSP90-1/2), R-BD (GAL4-BDGmRAR1), S1/S2-BD (GAL4-BD-GmSGT1-1/2), and AD (GAL4-AD vector with no fused protein). C, GmHsp90-1 and GmHsp90-2 expression in mock (M), vector-inoculated (V), or GmHsp90-1- and GmHsp90-2 (Hsp)-silenced plants (cv. Essex). RT-PCR analysis was carried out on cDNA from $4 \mu \mathrm{g}$ of total RNA from leaf tissues. Bean pod mottle comovirus (BPMV) was detected by amplifying RNA2 (BPMV-R2) and $\beta$-tubulin levels were used as internal control for cDNA amounts. D, Morphological phenotypes of $\mathrm{V}$ versus Hsp plants; i) plant height, ii) leaf size, and iii) increased axillary growth of Hsp plants. E, Bacterial counts at 0,3 , or 6 days postinfiltration of $\mathrm{V}$ or GmHSP90-1- and GmHSP90-2 (Hsp)silenced plants (cv. Harosoy), with avirulent ( $\operatorname{avrB})$ or virulent (vir) strains of $P$. syringae. script is also SA-inducible, although both the pathogen- and SA-induced levels are lower than those of GmSGT1-2. This, together with the fact that silencing GmSGT1-1 caused a nominal increase in the growth of $P$. syringae, suggests that GmSGT1-1 might also participate in soybean defense.

$\mathrm{R}$ proteins that recruit RAR1 or SGT1 often rely upon the HSP90 chaperone proteins for maintaining signaling competence (Bhattarai et al. 2007; Hubert et al. 2003; Liu et al. 2004; Takahashi et al. 2003). HSP90 is also required for $R x$-derived ER (Lu et al. 2003). Surprisingly, silencing two HSP90 isoforms in soybean did not alter defense responses to SMV or $P$. syringae. This suggests that, unlike in Arabidopsis, tobacco, or potato, HSP90 is not required for maintaining the functionality of R complexes in soybean. A second possibility is that functional redundancy in the HSP90 protein family compensates for GmHSP90-1 and GmHSP90-2 functions in the silenced plants. This is validated in Arabidopsis, where RPM1-mediated resistance is impaired in a functionally defective HSP90.2 mutant but not in a null mutant (Hubert et al. 2003). Related HSP90 isoforms likely compensate for the loss of HSP90.2 in the null mutant, whereas preferential binding of HSP90.2 to RPM1 might inhibit functional redundancy even in its nonfunctional form. Our results present the possibility that R proteins requiring RAR1 and SGT1 do not necessarily depend upon HSP90 for maintaining signaling competence. Alternatively, other chaperone proteins might be capable of providing $\mathrm{R}$ protein stability in soybean. Silencing GmHSP90-1 and GmHSP90-2 induced stunting and drastically altered morphology; therefore, it is possible that these isoforms only fulfill developmental functions. Indeed, HSP90s are known to participate in growth and development in tobacco and Arabidopsis (Liu et al. 2004; Sangster et al. 2007). Interestingly, the GmRARl-silenced plants also showed altered morphology suggesting that, in addition to defense, $R A R l$ may also contribute to soybean development.

Although RAR1 and SGT1 are largely recognized for their roles in ETI, recent studies have identified their functions in other modes of immunity as well. For example, RAR1 mediates basal resistance in Arabidopsis, barley, and rice (Holt et al. 2005; Jarosch et al. 2005; Thao et al. 2007; Wang et al. 2008). Silencing GmRARl and GmSGT1-2 in soybean resulted in increased susceptibility to virulent bacteria, indicating that these are also involved in PTI. The fact that GmRARI and GmSGT1-2 are also required for the induction of SAR in soybean suggests that RAR1 and SGT1 are intrinsic components of multiple modes of immunity in plants. Previous studies on AtSGT1b (Truman et al. 2007) and our present findings on AtRAR1 substantiate a requirement for these proteins in SAR in Arabidopsis as well. We conclude that diverse modes of immunity against virulent, avirulent, or secondary pathogens might be induced by fairly convergent signaling events downstream of pathogen recognition.

Our studies show that, although soybean defense signaling pathways recruit known components, the requirements for these proteins are fairly distinct. Furthermore, at least some of these "defense-related" components participate in developmental functions as well. Understanding the precise roles of these defense-related proteins could help in the development of improved strategies for crop protection.

\section{MATERIALS AND METHODS}

\section{Plant growth conditions.}

Soybean (G. $\max$ (L.) Merr.) plants were grown in the greenhouse with day and night temperatures of 25 and $20^{\circ} \mathrm{C}$, respectively. Inoculation with recombinant BPMV vectors was carried out at the VC stage (Pedersen 2004). Vector-inoculated 
and the various silenced plants were analyzed for various phenotypes at approximately the V3 growth stage. For each set of experiments, at least six to eight plants were inoculated with the vector or the various silencing constructs. Analysis of the effect of silencing was carried out using three to four separate sets of silenced plants for each phenotype. Cultivars used in this study are Essex or its isoline carrying the Rsv1 locus (L78379) (Bernard et al. 1991) for SMV-related studies and Harosoy for $P$. syringae-related studies. Demonstration of VIGS for each gene was carried out in cv. Essex. Arabidopsis plants (wild type or rarl mutant in Landsberg ecotype) were grown in the MTPS 144 Conviron walk-in chambers at $22^{\circ} \mathrm{C}, 65 \%$ relative humidity, and 14-h photoperiod. For stress treatments, soybean plants (V1 stage) were exposed to $4^{\circ} \mathrm{C}$ for $24 \mathrm{~h}$ (cold stress), $37^{\circ} \mathrm{C}$ for $24 \mathrm{~h}$ (heat stress), or not watered for $48 \mathrm{~h}$ after the soil was completely devoid of moisture (drought stress).

\section{Construction of viral vectors, in vitro transcription, and plant inoculation.}

For generating silencing vectors, target sequences were amplified from soybean cDNA using sequence-specific primers linked to BamHI (forward primer) and $M s c \mathrm{I}$ (reverse primer) sites and ligated to the BamHI/MscI-digested pGG7R2-V (Zhang and Ghabrial 2006). A 195-bp fragment encoding the K7-T71 region of GmRAR1, a 96-bp fragment encoding the Q212-I243 region of GmSGT1-1, and a 234-bp fragment encoding the P33-I110 region of GmSGT1-2 were used to target GmRAR1, GmSGT1-1, and GmSGT1-1, respectively. Plasmid constructs were used for in vitro transcription as previously described (Gu and Ghabrial 2005). Briefly, capped RNA transcripts were synthesized by incubating 1 to $5 \mu \mathrm{g}$ of linearized plasmids in a $100-\mu \mathrm{l}$ reaction mixture containing $40 \mathrm{mM}$ Tris$\mathrm{HCl}, \mathrm{pH} 7.5 ; 6 \mathrm{mM} \mathrm{MgCl}$; $2 \mathrm{mM}$ spermidine; $10 \mathrm{mM}$ dithiothreitol; 50 units of RNasin (Promega Corp., Madison, WI, U.S.A.); $0.5 \mathrm{mM}$ each ATP, CTP, and UTP; $0.1 \mathrm{mM}$ GTP; 0.5 $\mathrm{mM}$ cap-analogue $\left(\mathrm{m}^{7} \mathrm{G}\left(5^{\prime}\right) \mathrm{G}\right)$ (New England Biolabs, Ipswich, MA, U.S.A.); and 50 units of T7 RNA polymerase (New England Biolabs) at $37^{\circ} \mathrm{C}$ for $2 \mathrm{~h}$. RNA transcripts (RNA1 from strain K-Ho1 and recombinant RNA2) were used to rub inoculate fully expanded unifoliate leaves of soybean (VC stage).

RNA extraction, Northern, and RT-PCR analysis.

RNA from leaf, stem, and root tissues of soybean plants at the V1 or V2 growth stage and flower tissues at the R1 stage was extracted using the TRIzol reagent (Invitrogen, Carlsbad, CA, U.S.A.) as per the manufacturer's instructions. RNA from detached embryonic axles was extracted after soaking seed in sterile water overnight. For silencing experiments, RNA was extracted from BPMV-inoculated plants at the V3 stage. Northern blot analysis and synthesis of random-primed probes was as described before (Kachroo et al. 2001). RT and firststrand cDNA synthesis was carried out using Superscript II (Invitrogen). Two to three independent RNA preparations were analyzed at least twice by RT-PCR (35 amplification cycles). The number of amplification cycles was reduced to 23 to 25 for evaluating the relative difference in transcript levels in various samples.

\section{Primers, sequence accessions, and phylogenetic analysis.}

Primers for the various silencing constructs as well as for full-length sequences are as listed in Table 1. Primers were designed based on the full-length coding sequences available in the database for PR1 (AI930866) and $\beta$-tubulin (M21297). Sequence alignment and phylogenetic analysis of various genes was carried out using the Megalign program in the DNASTAR package (Swofford 2000).

\section{Pathogen inoculations and SA treatment.}

Pathogen inoculations were carried out at the V3 growth stage. All pathogen-inoculated plants were grown in a growth chamber at $22^{\circ} \mathrm{C}$ with a 16 -h photoperiod at $65 \%$ relative humidity. $P$. syringae pv. glycinea was grown on King's B medium containing kanamycin $(50 \mu \mathrm{g} / \mathrm{ml})$ and rifampicin $(750$ $\mu \mathrm{g} / \mathrm{ml})$, as appropriate, at $28^{\circ} \mathrm{C}$. M, V, and silenced plants at the V3 stage were infiltrated with bacterial suspensions at $1 \times$ $10^{5} \mathrm{CFU} / \mathrm{ml}$ in $10 \mathrm{mM} \mathrm{MgCl} 2$ plus $0.04 \%$ Silwett L-77. Mock inoculations were carried out with $10 \mathrm{mM} \mathrm{MgCl}_{2}$ in $0.04 \%$ Silwett L-77. Bacterial growth was monitored by dilution plating of homogenized leaf disks excised using a 1-cm cork borer at 0,3 , and 6 days postinoculation. At least five inoculated plants per treatment were sampled individually. Experiments were repeated three to four times. For Arabidopsis inoculations, bacterial suspensions in $10 \mathrm{mM} \mathrm{MgCl}_{2}$ were infiltrated in the abaxial surface of leaves using a 1-ml needleless syringe. Systemic acquired resistance was tested by infiltrating primary leaves with avirulent bacterial suspensions ( $a v r B$ for soybean or avrRpt 2 for Arabidopsis) at $1 \times 10^{7} \mathrm{CFU} / \mathrm{ml}$. After $48 \mathrm{~h}$ of primary infection, systemic leaves were inoculated with suspensions of virulent strains (Psg4 RUU1 for soybean and DC3000 for Arabidopsis) at $1 \times 10^{7} \mathrm{CFU} / \mathrm{ml}$, and the extent of proliferation of virulent bacteria was measured as before. For inoculation of SMV strain G2 (Cho and Goodman 1979), Car-

Table 1. Primers used for silencing and reverse-transcriptase polymerase chain reaction analysis of GmRAR1, GmSGT1-1 and GmSGT1-2, and GmHsp90-1 and GmHsp90-2 genes

\begin{tabular}{lll}
\hline Product & \multicolumn{1}{c}{ Purpose } & \multicolumn{1}{c}{ Sequence } \\
\hline GmRAR1 & Full-length transcript & Fwd-GAATGGAGAAGACAGCAGTT \\
& $\ldots$ & Rev-GCCGTCCAAACCAGCCAAAC \\
GmSGT1-1 & Full-length transcript & Fwd-CAGAAGCCAGAAGAAGTGGT \\
& $\ldots$ & Rev-CATCATGTTTACCATTATCA \\
GmSGT1-2 & Full-length transcript & Rev-GTCTCTCTCTCTCCCTCTCTC \\
& $\ldots$ & Fwd-CGACCATGGCGTGCCTCAA \\
GmHsp90-1 & Full-length transcript & Rev-GTCCTCGAGTTAATCACACCTCCTCCATT \\
& $\ldots$ & Fwd-CGACCATGGCTTCGGAGACT \\
GmHsp90-2 & Full-length transcript & Rev-CTGGGATCCTTAATCAACTTCTTCCATC \\
& $\ldots$ & Fwd-CATGGATCCAAAGTTCGATGCCAG \\
GmRAR1sil & Silencing vector & Rev-GACTGGCCATGTTGTATGTTTCC \\
GmSGT1-1sil & $\ldots$ & Fwd CATGGATCCCAACCTCGATTGTTGGA \\
& Silencing vector & Rev ACTTGGCCAAATAGCTTCAGCTTTTGC \\
GmSGT1-2sil & $\ldots$ & Fwd-CATGGATCCCCCAACAAAGCCGA \\
GmHsp90sil & Silencing vector & Rev-GACTGGCCAGATCAAAGTAGCAA \\
& $\ldots$ & Fwd-CATGGATCCATGGCGGAGACAGAGACG \\
& Silencing vector & Rev-ACTTGGCCAGAGTTCACGAAGGAAAATC \\
\hline
\end{tabular}


borundum-dusted (600-mesh) leaves of soybean were rub inoculated with sap from infected tissues in $50 \mathrm{mM}$ phosphate buffer, $\mathrm{pH}$ 7.0. SMV in leaf extracts was detected 10 to 14 days postinoculation using Northern and Western blot analysis as described (Anjos et al. 1992). Direct ELISA for SMV levels using SMV coat protein-specific antibodies was carried out as described previously (Calvert and Ghabrial 1983). Purified virions of SMV at concentrations of 10, 25, 50, 100, 250, 500, and $750 \mathrm{ng} / \mathrm{ml}$ were included in each ELISA plate. For SA treatment, soybean plants (V1) stage were sprayed with $1 \mathrm{mM}$ SA (until runoff) for 2 consecutive days.

\section{ACKNOWLEDGMENTS}

We thank A. Crume for help with managing the plant growth facility; Wendy Havens for technical support; A. Bogdanove, Iowa State University, for the Pseudomonas strains; and P. Kachroo for critically reviewing the manuscript. This work was supported by grants from the United States Department of Agriculture-National Research Initiative (2006-01854) and the United Soybean Board (project\#8244) to A. Kachroo and S. Ghabrial, National Science Foundation (MCB\#0421914) to A. Kachroo, and start-up funds from the Kentucky Agricultural Experiment Station to A. Kachroo. This study is publication no. 08-12-102 of the Kentucky Agricultural Experiment Station.

\section{LITERATURE CITED}

Anjos, J. R., Jarlfors, U., and Ghabrial, S. A. 1992. Soybean mosaic potyvirus enhances the titer of two comoviruses in dually infected soybean plants. Phytopathology 82:1022-1027.

Austin, M. J., Muskett, P., Kahn, K., Feys, B. J., Jones, J. D., and Parker, J. E. 2002. Regulatory role of SGT1 in early $R$ gene-mediated plant defenses. Science 295:2077-2080.

Ausubel, F. M. 2005. Are innate immune signaling pathways in plants and animals conserved? Nat. Immunol. 6:973-979.

Azevedo, C., Sadanandom, A., Kitagawa, K., Freialdenhoven, A., Shirasu, K., and Schulze-Lefert, P. 2002. The RAR1 interactor SGT1, an essential component of $R$ gene-triggered disease resistance. Science 295:2073-2076.

Azevedo, C., Betsuyaku, S., Peart, J., Takahashi, A., Noël, L., Sadanandom, A., Casais, C., Parker, J., and Shirasu, K. 2006. Role of SGT1 in resistance protein accumulation in plant immunity. EMBO (Eur. Mol. Biol. Organ.) J. 25:2007-2016.

Bernard, R. L., Nelson, R. L., and Caviness, C. R. 1991. USDA soybean genetic collection: Isoline collection. Soybean Genet. Newsl. 18:27-57.

Bhattarai, K. K., Li, Q., Liu, Y., Dinesh-Kumar, S. P., and Kaloshian, I. 2007. The Mi-1-mediated pest resistance requires Hsp90 and Sgt1. Plant Physiol. 144:312-323.

Bieri, S., Mauch, S., Shen, Q. H., Peart, J., Devoto, A., Casais, C., Ceron, F., Schulze, S., Steinbiss, H. H., Shirasu, K., and Schulze-Lefert, P. 2004. RAR 1 positively controls steady state levels of barley MLA resistance proteins and enables sufficient MLA6 accumulation for effective resistance. Plant Cell 16:3480-3495.

Bisgrove, S. R., Simonich, M. T., Smith, N. M., Sattler, A., and Innes, R. W. 1994. A disease resistance gene in Arabidopsis with specificity for two different pathogen avirulence genes. Plant Cell 6:927-933.

Botër, M., Amigues, B., Peart, J., Breuer, C., Kadota, Y., Casais, C., Moore, G., Kleanthous, C., Ochsenbein, F., Shirasu, K., and Guerois, R. 2007. Structural and functional analysis of SGT1 reveals that its interaction with HSP90 is required for the accumulation of Rx, an R protein involved in plant immunity. Plant Cell 19:3791-3804.

Buzzell, R. I., and Tu, J. C. 1984. Inheritance of soybean resistance to soybean mosaic virus. J. Hered. 75:82.

Calvert, L. A, and Ghabrial, S A. 1983. Enhancement by soybean mosaic virus of bean pod mottle virus titer in doubly infected soybean. Phytopathology 73:992-997.

Century, K. S., Holub, E. B., and Staskawicz, B. J. 1995. NDR1, a locus of Arabidopsis thaliana that is required for disease resistance to both a bacterial and a fungal pathogen. Proc. Natl. Acad. Sci. U.S.A. 92:65976601.

Chen, P., Buss, G. R., Roane, C. W., and Tolin, S. A. 1991. Allelism among genes for resistance to soybean mosaic virus in strain-differential soybean cultivars. Crop Sci. 31:305-309.

Chisholm, S. T., Coaker, G., Day, B., and Staskawicz, B. J. 2006. Hostmicrobe interactions: Shaping the evolution of the plant immune response. Cell 124:803-814.
Cho, E.-K., and Goodman, R. M. 1979. Strains of soybean mosaic virus: Classification based on virulence in resistant soybean cultivars. Phytopathology 69:467-470.

Csermely, P., Schnaider, T., Soti, C., Prohászka, Z., and Nardai, G. 1998. The $90-\mathrm{kDa}$ molecular chaperone family structure, function, and clinical applications. Compr. Rev. Pharmacol. Ther. 79:129-168.

Dangl, J. L., and Jones, J. D. 2001. Plant pathogens and integrated defence responses to infection. Nature 411:826-833.

Durrant, W. E., and Dong, X. 2004. Systemic acquired resistance. Annu. Rev. Phytopathol. 42:185-209.

Emanuelsson, O., Nielsen, H., Brunak, S., and von Heijne, G. 2000. Predicting subcellular localization of proteins based on their N-terminal amino acid sequence. J. Mol. Biol. 300:1005-1016.

Goebl, M., and Yanagida, M. 1991. The TPR snap helix: A novel protein repeat motif from mitosis to transcription. Trends Biochem. Sci. 16:173-177.

Grant, M. R., Godiard, L., Straube, E., Ashfield, T., Lewald, J., Sattler, A., Innes, R. W., and Dangl, J. L. 1995. Structure of the Arabidopsis RPMI gene enabling dual specificity disease resistance. Science 269: 843-846.

Gray, W. M., Muskett, P. R., Chuang, H. W., and Parker, J. E. 2003. Arabidopsis $\mathrm{SGT1b}$ is required for $\mathrm{SCF}^{\mathrm{TIR} 1}$-mediated auxin response. Plant Cell 15:1310-1319.

Gu, H., and Ghabrial, S. A. 2005. The Bean pod mottle virus proteinase cofactor and putative helicase are symptom severity determinants. Virology 333:271-283.

Heise, C. T., Le Duff, C. S., Boter, M., Casais, C., Airey, J. E., Leech, A. P., Amigues, B., Guerois, R., Moore, G. R., Shirasu, K., and Kleanthous, C. 2007. Characterization of RAR1 cysteine- and histidinerich domains (CHORDs): A novel class of zinc-dependent protein-protein interaction modules. Biochemistry 46:1612-1623.

Holt, B. F., Belkhadir, Y., and Dangl, J. L. 2005. Antagonistic control of disease resistance protein stability in the plant immune system. Science 309:929-932.

Hubert, D. A., Tornero, P., Belkhadir, Y., Krishna, P., Takahashi, A., Shirasu, K., and Dangl, J. L. 2003. Cytosolic HSP90 associates with and modulates the Arabidopsis RPM1 disease resistance protein. EMBO (Eur. Mol. Biol. Organ.) J. 22:5679-5689.

Jarosch, B., Collins, N. C., Zellerhoff, N., and Schaffrath, U. 2005. RAR1, ROR1, and the actin cytoskeleton contribute to basal resistance to Magnaporthe grisea in barley. Mol. Plant-Microbe Interact. 18:397-404.

Kachroo, A., Fu, D. Q., Havens, W., Navarre, D., Kachroo, P., and Ghabrial, S. A. 2008. An oleic acid-mediated pathway induces constitutive defense signaling and enhanced resistance to multiple pathogens in soybean. Mol. Plant-Microbe Interact. 21:564-575.

Kachroo, P., Shanklin, J., Shah, J., Whittle, E. J., and Klessig, D. F. 2001. A fatty acid desaturase modulates the activation of defense signaling pathways in plants. Proc. Natl. Acad. Sci. U.S.A. 98:9448-9453.

Kanzaki, H., Saito, H., Ito, A., Fujisawa, S., Kamoun, S., Katou, S., Yoshioka, H., and Trauchi, R. 2003. Cytosolic HSP90 and HSP70 are essential components of INF1-mediated hypersensitive response and non-host resistance to Pseudomonas cichorii in Nicotiana benthamiana. Mol. Plant Pathol. 4:383-391.

Lamb, J. R., Tugendreich, S., and Hieter, P. 1995. Tetratricopeptide repeat interactions: To TPR or not to TPR? Trends Biochem. Sci. 20:257-259.

Lim, S. M. 1985. Resistance to soybean mosaic virus in soybeans. Phytopathology 75:199-201.

Liu, D., Zhang, X., Cheng, Y., Takano, T., and Liu, S. 2006. rHsp90 gene expression in response to several environmental stresses in rice (Oryza sativa L.). Plant Physiol. Biochem. 44:380-386.

Liu, Y., Burch-Smith, T., Schiff, M., Feng, S., and Dinesh-Kumar, S. P. 2004. Molecular chaperone Hsp90 associates with resistance protein N and its signaling proteins SGT1 and Rar1 to modulate an innate immune response in plants. J. Biol. Chem. 279:2101-2108.

Lu, R., Malcuit, I., Moffett, P., Ruiz, M. T., Peart, J., Wu, A. J., Rathjen, J. P., Bendahmane, A., Day, L., and Baulcombe, D. C. 2003. High throughput virus-induced gene silencing implicates heat shock protein 90 in plant disease resistance. EMBO (Eur. Mol. Biol. Organ.) J. 22:5690-5699.

Muskett, P., and Parker, J. 2003. Role of SGT1 in the regulation of plant $R$ gene signaling. Microbes Infect. 5:969-976.

Muskett, P. R., Kahn, K., Austin, M. J., Moisan, L. J., Sadanandom, A., Shirasu, K., Jones, J. D., and Parker, J. E. 2002. Arabidopsis RAR1 exerts rate-limiting control of $\mathrm{R}$ gene-mediated defenses against multiple pathogens. Plant Cell 14:979-992.

Nimchuk, Z., Eulgem, T., Holt, B. F., and Dangl, J. L. 2003. Recognition and response in the plant immune system. Annu. Rev. Genet. 37:579-609.

Parker, J. E., Holub, E. B., Frost, L. N., Falk, A., Gunn, N. D., and Daniels, M. J. 1996. Characterization of edsl, a mutation in Arabidopsis suppressing resistance to Peronospora parasitica specified by RPP genes. Plant Cell 8: 2033-2046. 
Peart, J. R., Lu, R., Sadanandom, A., Malcuit, I., Moffett, P., Brice, D. C., Schauser, L., Jaggard, D. A., Xiao, S., Coleman, M. J., Dow, M., Jones, J. D., Shirasu, K., and Baulcombe, D. C. 2002. Ubiquitin ligase-associated protein SGT1 is required for host and nonhost disease resistance in plants. Proc. Natl. Acad. Sci. U.S.A. 99:10865-10869.

Pedersen, P. 2004. Soybean growth and development stages. Publication no. PM1945. Iowa State University Extension, Ames, IA, U.S.A.

Sangster, T. A., Bahrami, A., Wilczek, A., Watanabe, E., Schellenberg, K., McLellan, C., Kelley, A., Kong, S. W., Queitsch, C., and Lindquist, S. 2007. Phenotypic diversity and altered environmental plasticity in Arabidopsis thaliana with reduced Hsp90 levels. PLoS ONE 2:e648.

Schulze-Lefert, P. 2004. Knocking on the heaven's wall: Pathogenesis of and resistance to biotrophic fungi at the cell wall. Curr. Opin. Plant Biol. 7:377-383.

Shang, Y., Li, X., Cui, H., He, P., Thilmony, R., Chintamanani, S., ZwieslerVollick, J., Gopalan, S., Tang, X., and Zhou, J. M. 2006. RAR1, a central player in plant immunity, is targeted by Pseudomonas syringae effector AvrB. Proc. Natl. Acad. Sci. U.S.A. 103:19200-19205.

Shirasu, K., and Schulze-Lefert, P. 2003. Complex formation, promiscuity and multi-functionality: Protein interactions in disease-resistance pathways. Trends Plant Sci. 8:252-258.

Shirasu, K., Lahaye, T., Tan, M. W., Zhou, F., Azevedo, C., and SchulzeLefert, P. 1999. A novel class of eukaryotic zinc-binding proteins is required for disease resistance signaling in barley and development in C. elegans. Cell 99:355-366.

Swofford, D. L. 2000. PAUP: Phylogenetic Analysis Using Parsimony and Other Methods (software). Sinaur Associates, Sunderland, MA, U.S.A.

Takahashi, A., Casais, C., Ichimura, K., and Shirasu, K. 2003. HSP90 interacts with RAR1 and SGT1 and is essential for RPS2-mediated disease resistance in Arabidopsis. Proc. Natl. Acad. Sci. U.S.A. 100:11777-11782.

Thao, N. P., Chen, L., Nakashima, A., Hara, S., Umemura, K., Takahashi, A., Shirasu, K., Kawasaki, T., and Shimamoto, K. 2007. RAR1 and
HSP90 form a complex with Rac/Rop GTPase and function in innateimmune responses in rice. Plant Cell 19:4035-4045.

Tör, M., Gordon, P., Cuzick, A., Eulgem, T., Sinapidou, E., Mert-Türk, F, Can, C., Dangl, J. L., and Holub, E. B. 2002. Arabidopsis SGT1b is required for defense signaling conferred by several downy mildew resistance genes. Plant Cell 14:993-1003.

Tornero, P., Merritt, P., Sadanandom, A., Shirasu, K., Innes, R. W., and Dangl, J. L. 2002. RAR1 and NDR1 contribute quantitatively to disease resistance in Arabidopsis, and their relative contributions are dependent on the R gene assayed. Plant Cell 14:1005-1015.

Torp, J., and Jorgensen, J. H. 1986. Modification of barley powdery mildew resistance gene $\mathrm{Mlal}_{2}$ by induced mutation. Can. J. Genet. Cytol. 28: 725-731.

Truman, W., Bennett, M. H., Kubigsteltig, I., Turnbull, C., and Grant, M. 2007. Arabidopsis systemic immunity uses conserved defense signaling pathways and is mediated by jasmonates. Proc. Natl. Acad. Sci. U.S.A. 104:1075-1080.

Wang, Y., Gao, M., Li, Q., Wang, L., Wang, J., Jeon, J. S., Qu, N., Zhang, Y., and He, Z. 2008. OsRAR1 and OsSGT1 physically interact and function in rice basal disease resistance. Mol. Plant-Microbe Interact. 21:294-303.

Yamada, K., Fukao, Y., Hayashi, M., Fukazawa, M., Suzuki, I., and Nishimura, M. 2007. Cytosolic HSP90 regulates the heat shock response that is responsible for heat acclimation in Arabidopsis thaliana. J. Biol. Chem. 282:37794-37804.

Zhang, C., and Ghabrial, S. A. 2006. Development of Bean pod mottle virusbased vectors for stable protein expression and sequence-specific virusinduced gene silencing in soybean. Virology 344:401-411.

\section{AUTHOR-RECOMMENDED INTERNET RESOURCE}

SoyBase EST database: soybase.org/Blast_Search.php 